\title{
Narrativas sobre el silencio. Las voces de los docentes en la dinámica escolar de una alumna con discapacidad auditiva
}

Narratives About Silence. Teacher's Voices in the School Dynamics of a Student with Hearing Impairment

Narrativas sobre o silêncio. As vozes dos professores na dinâmica escolar de um aluno com deficiência auditiva

Soledad Hernández Solís

Universidad de Ciencias y Artes de Chiapas, México

soledad.hernandez@unicach.mx https://orcid.org/0000-0001-5621-986X

Germán Alejandro García Lara

Universidad de Ciencias y Artes de Chiapas, México german.garcia@unicach.mx https://orcid.org/0000-0002-4075-4988

Irma Hernández Solís Universidad de Ciencias y Artes de Chiapas, México irma.hernandez@unicach.mx https://orcid.org/0000-0001-7335-7519

Carlos Eduardo Pérez Jiménez Universidad de Ciencias y Artes de Chiapas, México carlos.perez@unicach.mx https://orcid.org/0000-0001-7051-9017 
Oscar Cruz Pérez

Universidad de Ciencias y Artes de Chiapas, México oscar.cruz@unicach.mx https://orcid.org/0000-0003-2452-2834

\section{Resumen}

En muchas culturas, las niñas y los niños con condición de discapacidad vivencian menoscabo de su dignidad: no solo tienen que luchar de forma desigual ante sus pares por su condición, sino que también tienen menos oportunidades de aprendizaje y participación en la escuela regular. Por ello, en este trabajo se profundiza en las narrativas sobre la dinámica escolar de una alumna con condición de discapacidad auditiva. Se utiliza la investigación cualitativa en un estudio de caso mediante registros de observación en diferentes situaciones de la actividad escolar de la alumna, así como entrevistas semiestructuradas a los docentes de aula regular, Educación Física, Música y del Centro de Atención Múltiple de Educación Especial. El análisis de la información posibilitó la conformación de dos bloques temáticos: "Una alumna con sordera. Lo que sabe, lo que intenta y lo que le permiten hacer", donde se analizan las concepciones y prácticas de los docentes, y "Pertrechos y faltas en la estructuración sociocognitiva y la convivencia social”, donde se describen los recursos y carencias de la alumna. En ambos bloques, se hace especial énfasis en el proceso comunicativo. Finalmente, se encuentra que, en la práctica, el profesorado que atiende a la alumna no utiliza una comunicación adecuada ni estrategias didácticas y metodológicas para una enseñanza acorde a sus posibilidades de aprendizaje y aplican una acción didáctica indiferenciada entre ella y sus compañeros. Aunque la constitución política local expresa la necesidad de crear ambientes inclusivos para los niños sordos, al no considerar las diferencias individuales y el lenguaje de señas en la comunicación, se le excluye del entorno académico, de los juegos, la amistad y el mundo social. En este contexto, es indispensable reconocer el derecho a una educación en donde se garantice la enseñanza en la lengua de señas mexicana y unidades de apoyo en la escuela regular para este tipo de alumnos.

Palabras clave: comunicación, discapacidad auditiva, inclusión, práctica docente. 


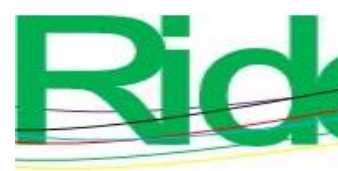

Revista Iberoamericana para la Investigación y el Desarrollo Educativo ISSN 2007 - 7467

Música e Centro de Atenção Múltipla da Educação Especial. A análise das informações possibilitou a formação de dois blocos temáticos: "Um aluno com surdez. O que ele sabe, o que tenta e o que lhe permitem fazer ", onde são analisadas as concepções e práticas dos professores, e" Vantagens e falhas na estruturação sociocognitiva e na convivência social ", onde se encontram os recursos e deficiências do aluno. Em ambos os blocos, ênfase especial é colocada no processo comunicativo. Por fim, constata-se que, na prática, os professores que atendem o aluno não utilizam estratégias adequadas de comunicação ou didáticometodológicas para o ensino de acordo com suas possibilidades de aprendizagem e aplicam uma ação didática indiferenciada entre ela e seus colegas. Embora a constituição política local expresse a necessidade de criar ambientes inclusivos para as crianças surdas, por não considerar as diferenças individuais e a língua de sinais na comunicação, elas são excluídas do meio acadêmico, dos jogos, da amizade e do mundo social. Neste contexto, é fundamental reconhecer o direito a uma educação onde seja garantido o ensino da língua de sinais mexicana e unidades de apoio na escola regular para este tipo de alunos.

Palavras-chave: comunicação, deficiência auditiva, inclusão, prática docente.

Fecha Recepción: Agosto 2020

Fecha Aceptación: Febrero 2021

\section{Introducción}

El propósito del presente trabajo es dar cuenta del sentido de las prácticas escolares para una alumna con condición de discapacidad auditiva, de intentar tejer la trama bajo la cual se sonorizan las voces de sus docentes y compañeros, entretejido que aliente la comprensión de los retos y dificultades de esta tarea educativa para acompañar la reconstrucción de dichas experiencias.

Cuando en el proceso de enseñanza-aprendizaje se incluye a escolares con condiciones de discapacidad queda especialmente al descubierto el desafío y la trascendencia de la labor del docente. La convergencia de los saberes o las experiencias que se cristalizan en los encuentros entre maestros y alumnos, en un entorno de diversidad, tiene como marco a la institución escolar y el currículo, sí, pero también un contexto social y económico que media la vida social, la organización del trabajo y la estructuración de las familias, cuya compleja y desigual condición permea indudablemente la propia realidad escolar. Recrear y articular respuestas a las demandas de los educandos, muchas veces sin los recursos humanos y materiales de profesionalización suficientes, es el escenario en que discurre y se significa 


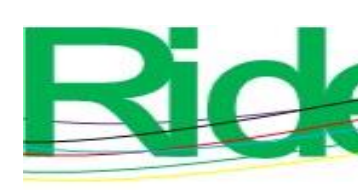

Revista Iberoamericana para la Investigación y el Desarrollo Educativo ISSN 2007 - 7467

la práctica docente. Cabe señalar que esta, la práctica docente, se integra por el conjunto de prácticas sociales en que se comparten saberes con los educandos (Ávalos, 2002), conjunto que tiene un carácter intencional e históricamente localizado (Carr y Kemmis, 1988).

Los saberes pueden ser de sentido común, populares, destrezas, contextuales, profesionales, morales y sociales (Carr y Kemmis, 1988). La relación que se sucede entre el saber con el hacer, en las actuaciones, procedimientos y actividades intencionadas, configura las estrategias de enseñanza, una de cuyas perspectivas de valoración considera su análisis mientras transcurre, a partir del "papel de lo espontáneo, las intuiciones y la conformación de una sabiduría práctica" (Litwin, 2008, p. 23). Sin duda se trata de situaciones a las que se aúna la incertidumbre y el conflicto; muchas razones se imbrican para la ejecución de ciertas acciones en tiempo real, las cuales se interpretan y expanden permanentemente en el campo de la experiencia; de ahí que su apreciación deberá ser realizada desde una lógica proversiva.

Una práctica no se funda necesariamente en teorías pedagógicas; más aún, deviene de los conocimientos y experiencias prácticas (Litwin, 2008). Para Carr y Kemmis (1988), allí radica la raigambre de la acción estratégica, "informada por cierto marco de pensamiento y racionalidad y cuenta además con una práctica que le confiere significado material" (p. 58).

Tales estrategias y experiencias de la actividad práctica son aspectos cardinales para la comprensión del acontecer cotidiano en las aulas, y de particular relevancia para aquel profesorado que despliega su práctica docente en entornos de diversidad. Booth y Ainscow (2015) explican la educación inclusiva como el conjunto de procesos que tiene como objetivo eliminar o reducir las barreras que limitan el aprendizaje y la participación de todos los estudiantes. Para la Organización de las Naciones Unidas para la Educación, la Ciencia y la Cultura [Unesco] (2005), es un proceso orientado a responder a la diversidad del alumnado, con especial énfasis en aquellos que, por diferentes razones, están excluidos o en riesgo de ser marginados, como es el caso de escolares con condición de discapacidad.

La discapacidad remite a que algo de lo esperado como potencialidad no se presenta en una persona al igual que en otra. Se centra en lo orgánico, en el déficit, en la falta de capacidad sensorial, intelectual o motriz, aunque su comprensión ha variado de acuerdo con los imaginarios sociales de cada cultura (Schorn, 2009). Se concibe como una restricción o ausencia de la capacidad de realizar una actividad de la forma o dentro del margen que se considera normal para cualquier humano. Se caracteriza por insuficiencias o excesos en el desempeño y comportamiento en una actividad rutinaria, que pueden ser temporales o 


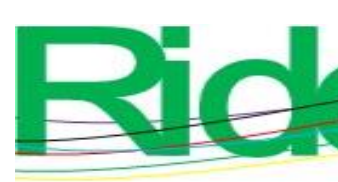

Revista Iberoamericana para la Investigación y el Desarrollo Educativo ISSN $2007-7467$

permanentes, reversibles o irreversibles y progresivos o regresivos (Cáceres, 2004). Sin embargo, también puede ser entendida de la siguiente forma:

Es una construcción relacional entre la sociedad y un sujeto (individual o colectivo) (...). La discapacidad es entonces el espacio contingente y arbitrario que se le asigna a ese sujeto y por lo tanto la situación de desventaja aumenta o disminuye en función de su contexto social (y económico) (Brogna, 2006, p. 2).

Uno de los grupos con esta condición es el de aquellos con deficiencia auditiva e hipoacusia.

Los alumnos con discapacidad auditiva presentan alteraciones en diferentes ámbitos del desarrollo infantil (Puigdellívol, 2003), por ejemplo, en el cognitivo, donde existe un desfase temporal en la adquisición de habilidades lógicas operacionales y de pensamiento formal, así como en lo comunicativo y linguiístico. También presentan limitaciones en el juego simbólico, en la capacidad de anticipar situaciones de autorregulación, producto de la mínima información a la que tienen acceso, ya que mucha de esta se transmite de forma oral (Marchesi, Coll y Palacios, 2014). Y en el desarrollo afectivo-social, debido a la dependencia con el adulto o el cuidador principal (Puigdellívol, 2000). Respecto al área psicomotriz, se manifiesta, en algunos casos, torpeza motora, andar pesado y poco seguro, entre otros aspectos.

Tales retrasos acontecen no necesariamente por la condición de sordera, sino por la falta de estimulación y apoyo temprano en el lenguaje de señas. Por ejemplo, en familias donde otros de sus integrantes tienen la misma condición y este apoyo se presenta, no se suscitan dichos retrasos.

Desde la perspectiva de la hipótesis conversacional (Peterson y Siegal, 1999), el retraso se explica en función de la escasa interacción conversacional que estos niños mantienen con sus padres a una edad temprana. Esta falta de input conversacional sobre estados mentales ajenos y propios coloca a los niños con discapacidad auditiva en una situación de clara desventaja respecto a sus iguales signantes nativos y oyentes (Peterson, 2004).

Las personas con discapacidad auditiva viven en una sociedad formada por oyentes, lo que las enfrenta a barreras comunicativas que les dificultan el acceso a la información y a la comunicación en el contexto escolar y social y obstaculizan con frecuencia su desarrollo personal, social y laboral, ya que el lenguaje se erige como un instrumento que vertebra las 


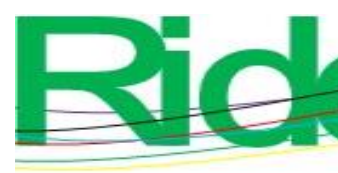

Revista Iberoamericana para la
Investigación y el Desarrollo Educativo
ISSN $2007-7467$

comunicarse pronto, fácil y de forma más amplia, a diferencia de aquellos que solo se comunican oralmente. El niño que primero aprende el lenguaje de señas y otras formas de comunicación habla y lee los labios más fácilmente.

La distancia entre las previsiones y diseños que se sostienen para la escuela inclusiva, interrumpida en tiempo y espacio por la realidad de cada centro escolar y su profesorado, demandas narrativas en que converjan ambas perspectivas.

\section{Método}

El estudio se aborda desde un paradigma interpretativo, el cual profundiza en la comprensión y significado de la realidad, considerando las limitaciones contextuales de carácter económico, social y cultural en que se implican tanto el investigador como los participantes del estudio (Álvarez, 2007). En un escenario escolar, se contribuye a comprender, conocer y actuar frente a situaciones cotidianas del hecho educativo (Ricoy, 2005).

\section{Técnicas de recopilación de información}

Se aplicó la observación no participante, procedimiento en el que no se tiene intervención directa y relación con los sujetos; se opera como un espectador, tomando nota de cuanto ocurre, en este caso a través de registros de diario de campo (Campos y Lule, 2012). Además, se utilizó la entrevista abierta, dirigida a los docentes de aula regular, Música y Educación Física y del Centro de Atención Múltiple.

\section{Participantes}

Abril $^{1}$ es una niña de cinco años. La mamá de Abril tuvo un embarazo de alto riesgo y dio a luz mediante cesárea. No se refieren problemas peri y posnatales, tampoco en la lactancia y desarrollo inicial, aunque se comprobó disminución auditiva, situación que se exploró debido a que la madre presenta pérdida auditiva profunda. Abril mostró dificultades en el desarrollo del lenguaje, por lo asistió durante dos años a la Escuela de Audición y Lenguaje. Posteriormente, a partir de segundo grado de preescolar, fue referida a una escuela regular.

\footnotetext{
${ }^{1}$ Nombre ficticio de la alumna.
} 


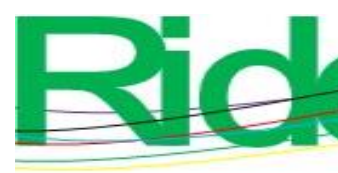

Revista Iberoamericana para la Investigación y el Desarrollo Educativo ISSN $2007-7467$

La maestra de aula regular es licenciada en Educación Preescolar, tiene 56 años de edad y 33 años de servicio. Es la responsable del grupo de tercer grado, que cuenta con 29 alumnos, uno de los cuales es Abril. Tiene un hijo sordo, por lo que se mostró dispuesta a atenderla cuando se lo solicitaron: asumió que dichos antecedentes le habilitarían en la tarea de enseñanza.

Otros docentes son el maestro de Música, quien es licenciado en Música, tiene 38 años de edad y 12 de servicio; la maestra de Educación Física, quien cursó la licenciatura en esta área e imparte las clases correspondientes, tiene 52 años de edad y 29 años laborando en el magisterio.

Además, participaron dos maestras del Centro de Atención Múltiple, servicio de la modalidad de educación especial que brinda apoyo complementario a escolares con estas características.

\section{Contexto del estudio}

El estudio se realizó en el Jardín de Niños Justo Sierra de Tuxtla Gutiérrez, Chiapas, México. De manera inicial, se estableció contacto con la abuela materna de la niña y con la propia Abril. En este primer acercamiento se les compartió el interés por realizar el seguimiento de la práctica escolar de Abril y obtuvimos el consentimiento informado y autorización para realizar actividades de observación. Posteriormente, se solicitó a la directora del plantel su autorización para llevar a cabo la investigación. De manera general, se le explicó el trabajo a realizar y, en reunión con el pleno de docentes, se expusieron los aspectos más relevantes del estudio, aquí también hubo anuencia y apoyo. Con los profesores se acordaron los días y horarios de visita a la institución, con la intención de observar el trabajo en las diferentes actividades escolares en las que participa Abril, así como los horarios para la realización de entrevistas a los docentes, lo que se complementó con múltiples charlas de carácter informal en el curso de la investigación realizada durante el ciclo escolar.

\section{Análisis de información}

Una vez recopilada la información, se utilizó el procedimiento de análisis planteado por Bardín (2002), que incluye inferencias a partir de información verbal, simbólica o comunicativa para la construcción de categorías, las cuales fueron agrupadas en 


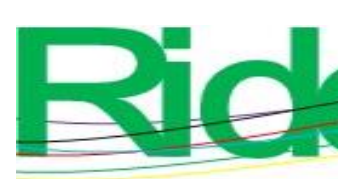

Revista Iberoamericana para la
Investigación y el Desarrollo Educativo
ISSN $2007-7467$

metacategorías analíticas a fin de ordenar y jerarquizar los datos obtenidos; así fue posible alcanzar una mayor comprensión de estos y se procedió a su descripción e interpretación.

\section{Resultados}

Una vez realizadas y transcritas las entrevistas y registros de observación, se llevó a cabo el análisis de contenido, proceso a partir del cual fue posible la conformación de dos bloques temáticos: "Una alumna con sordera. Lo que sabe, lo que intenta y lo que le permiten hacer", donde se profundiza en el análisis de las concepciones, actividades de apoyo y prácticas de los docentes en la actividad escolar con una alumna con hipoacusia, y "Pertrechos y faltas en la estructuración sociocognitiva y la convivencia social", donde se describen aquellos recursos y falencias sociales, cognitivas y afectivas de la alumna. En ambos bloques se hace especial énfasis en el proceso comunicativo.

\section{Una alumna con sordera. Lo que sabe, lo que intenta y lo que le permiten hacer}

Los registros de observación y entrevistas permitieron contar con un panorama amplio de las prácticas de los docentes tanto durante la enseñanza de la escritura, la lectura, matemáticas, la elaboración de dibujos y actividades plásticas como durante las clases de Educación Física y Música, al igual que de sus concepciones en la actividad escolar con una alumna con hipoacusia.

Abril ingresó a la escuela en el segundo grado de preescolar, adecuándose sin dificultades a la actividad escolar; mostró competencias sobre todo en el copiado de la escritura y recorte, lo que le permitió realizar actividades sin diferencia al resto de sus compañeros e incluso apoyarles, tal como refiere la maestra de grupo:

Ella le ayuda a sus compañeros a escribir su nombre, porque tiene al lado a su primita Ivonne. Entonces le digo:

-Ivonne, ¡escribe bien tu nombre, ya eres una niña de tercero!

Abril le escribe su nombre a Ivonne, iy se lo escribe bien!, ella se lo copia, e incluso hasta los trabajos se los hace a veces, porque ella dice que no puede, por ejemplo, recortar (entrevista número tres).

Una secuencia didáctica comúnmente aplicada por la maestra se basa en la aplicación de consignas, realización por los alumnos de la actividad propuesta, el diálogo y supervisión 


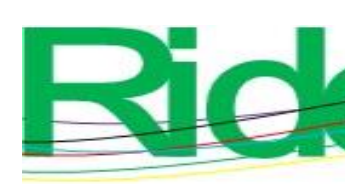

Revista Iberoamericana para la
Investigación y el Desarrollo Educativo
ISSN $2007-7467$

de la tarea mediante preguntas y respuestas. En estas actividades, Abril no siempre participa, pues, al no escuchar a la maestra ni existir una instrucción pertinente a su condición, se distrae y realiza dibujos en la mesa de trabajo, juega con los objetos a su alcance y se desplaza de una mesa a otra, aunque se esfuerza por seguir las indicaciones, observa cómo lo hacen sus compañeros o intenta leer los labios a la maestra.

Para el desarrollo de la lectura, tarea particularmente compleja que demanda la escucha y la oralización, la maestra inicia con instrucciones generales al grupo, sin una consigna específica para Abril, quien batalla en su ejecución:

Abril voltea a ver a sus compañeros y mediante la lectura de labios trata de comprender las indicaciones a la par de observar lo que realizan. Cuando logra ver de manera frontal a la maestra, repite lo que dice siguiendo el movimiento de sus labios; no obstante, no repite todas las palabras, solo hace el movimiento con la boca, por lo que su comprensión la complementa imitando las acciones de los compañeros. Se dirige al lugar de los cuentos y toma un libro junto a su prima, con quien juega mientras exploran los materiales. Una vez que elige un libro, observa inmediatamente a sus compañeros y se guía de lo que ellos hacen, corroborando su propio accionar.

Después de un determinado tiempo, la maestra les ordenó que pusieran los cuentos en su lugar y les preguntó:

— ¿Quién quiere pasar a leer su cuento?

Muchos levantaron la mano y participaron frente del grupo, describiendo las imágenes observadas. Después, la maestra solicitó a los alumnos que pasaran al frente para que nombraran las letras que encontraron en el texto, señalando entre aquellas que se listan en un letrero situado en una de las paredes del aula.

Cuando un niño habla, Abril observa sus labios y lo que señala. Cuando le correspondió el turno a ella, repitió lo mismo que dijo el niño anterior, imitando su respuesta y movimientos de labios. Señaló la letra $a$, mientras lo hace, abre totalmente la boca, después la cierra para indicar y decir la $o$, para ello, emite un sonido mientras suelta el aire, con bajo volumen; para la letra $s$ no se identifica el movimiento de la boca, pues no logra pronunciar el nombre de ella y, finalmente, con la letra $p$ cierra los labios apretándolos y expresa “pa”. Mientras menciona las letras gesticula con los 


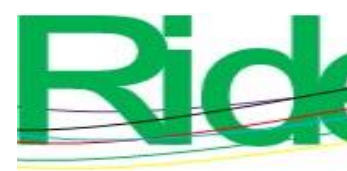

Revista Iberoamericana para la
Investigación y el Desarrollo Educativo
ISSN $2007-7467$

labios e intenta emitir los sonidos, mira a su prima para recibir su ayuda (observación número siete).

La imitación es un recurso importante en el aprendizaje de un niño, pero muy pronto, al ingresar a otro nivel escolar, donde los contenidos son cada vez más abstractos, serán indispensables otros recursos; es probable que las futuras exigencias académicas le deparen dificultades de aprendizaje en diversos ámbitos, sin considerar la afectación en su estructuración psíquica, sobre todo si no se consideran adecuaciones al trabajo docente que facilite su aprendizaje.

En Matemáticas, la maestra infiere sobre la competencia de la alumna y señala:

¡Ella sabe!, ¡identifica los números y las cantidades! Ella sabe, por ejemplo, si le pongo el número uno, dos y tres (entrevista número tres).

Más allá de estos logros, la capacidad imitativa de lo que los otros realizan tiene límites ante los procesos de abstracción que supone la representación paritaria de objetos en que uno de estos asume cierto valor (número) y la realización de sumas; si bien identifica y es capaz de nombrar ciertos numerales, la noción de cantidad aún no la ha construido.

La maestra les dice a los alumnos que tomen su ábaco para realizar operaciones matemáticas. Les explica que, en el ábaco, las fichas amarillas tienen un valor de dos, las fichas azules de cinco y las rojas de uno. Escribe en el pizarrón, de forma horizontal, la operación: $2+5+1$. Les pide que copien esta, usen el ábaco para realizar la suma y escriban el resultado. Algunos niños se acercan a la maestra para preguntarle si lo hacen bien, así como los valores de los colores; Abril no pregunta cómo debe realizar la operación, opta por imitar y copiar de su compañero de al lado, a quien voltea a ver constantemente la actividad que realiza.

Durante la actividad, la maestra camina alrededor de las mesas, los niños le llaman y les atiende, pero no se acerca a Abril, quien toma su ábaco e imita lo que hace su prima y copia las respuestas que registra en su hoja. Cuando terminan de hacer las operaciones, la maestra le pregunta a Abril cuáles son los números que señala (previamente escribió en el pizarrón el número 15), ella responde mencionando los nombres de cada número (uno y cinco) con voz muy tenue, representando cada numeral con los dedos (observación número seis). 


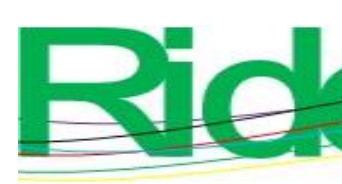

Revista Iberoamericana para la Investigación y el Desarrollo Educativo ISSN $2007-7467$

continúa trabajando con su figura, sin prestar atención a la maestra. Minutos después, la maestra dice:

— ¡Ya tenemos ganador y el ganador es: todoooooos!

Los alumnos gritan y aplauden, otros abuchean y Abril se queda seria y aplasta su figura (observación número dos).

Esta disposición general de las instrucciones es reiterada por la maestra de grupo en la entrevista:

Bueno, las indicaciones que les hago las realizo sin centrarme solo en ella, ¡es que son tantos niños y en ocasiones me olvido que ella no escucha! (entrevista número dos).

Los niños sordos, al no comprender el sentido de las actividades que se les proponen, optan por explorar su mundo de nuevas maneras, acorde a su condición. Según la mirada de la maestra o de los compañeros de clase, se tornan inquietos o indisciplinados. En ocasiones, su soledad y aislamiento no encuentran otro modo de exteriorización que la agresividad (Vesga y Vesga, 2015), tal y como se aprecia en la viñeta referida al modelado con plastilina.

En Educación Física, la interacción con Abril es bastante similar a la que ocurre en el aula de clases. Por un lado, se reitera la falta de una atención diferenciada acorde a su condición para la comprensión de las actividades, y por otro, sus dificultades en la realización de algunas acciones, con la consecuente frustración.

La maestra les pregunta a gritos:

-¿Cómo están? ¿Están listos para trabajar el día de hoy?

Ellos responden con gritos: “¡bien!, ¡síii!”. Abril sonríe, salta e imita a sus compañeros, pero no emite ningún sonido, solo abre la boca, efectúa movimientos afirmativos y aplaude, sin perder de vista lo que ellos realizan. La maestra les dice que realizarán una carrera de obstáculos, por equipos, en grupos de cinco, explica las reglas del juego, mientras lo hace les habla en voz alta, sin una explicación específica para Abril, quien intenta colocarse lo más cerca de la maestra para verla, también busca la cara de su prima y le hace movimientos con las manos, le pide que le explique qué van a hacer, le jala del brazo y señala a la maestra. Ivonne le dice que espere, mientras la maestra continúa la explicación sobre la actividad. Durante esta, Abril se mantiene sonriente al lado de su prima, viendo lo que hacen sus compañeros; llega su turno, en cada cambio de obstáculo dirige su mirada hacia su prima 


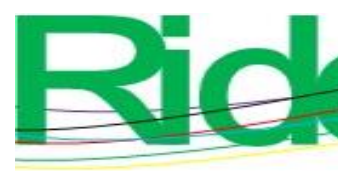

Revista Iberoamericana para la Investigación y el Desarrollo Educativo ISSN $2007-7467$

y después a la maestra, todos le gritan motivándola a que se apure. Al llegar a las pelotas, ella tiene que encestar, pero no puede hacerlo, en varias ocasiones voltea a ver a su prima, le hace gestos para que la ayude, su prima le dice cómo debe de hacerlo y le enseña desde lejos, los demás compañeros se ríen y le gritan que se apure, no logra hacerlo y la maestra le hace una seña para que continúe con el siguiente obstáculo. Abril se molesta, no termina con el circuito, se aparta del equipo y no sigue participando. Se sienta bajo de un árbol, la maestra no se acerca a Abril, permite que se aleje del grupo, los demás alumnos continúan con la actividad. A los 10 minutos se acerca su prima a ella, la abraza y le pide que regrese al equipo, intenta llevarla, jalándola hacia ellos. Abril se resiste, pero al fin accede y se vuelve a integrar al grupo. Cuando lo hace, la maestra le dice: “¡Bien, Abril, regresaste, vamos, sigamos jugando!” (observación número cuatro).

Al igual que con el modelamiento, algunas actividades deportivas le son sumamente difíciles de realizar y su respuesta es de frustración, de enojo, lo que la lleva a aislarse y a negarse a participar o concluir la tarea. Otras tareas, al igual que en aquellas en las que muestra competencia, le complacen y las disfruta. Por ejemplo, las desarrolladas en Música, espacio en el que se funde con el resto de los compañeros y no hay una actividad por concluir o una acción por ejecutar sola, a la vista de los demás. La incapacidad para comprender y realizar las actividades diseñadas para los oyentes, lo mismo que sus reacciones agresivas, a la larga afectan al niño sordo en su integralidad como ser humano (Herrera, 2009).

El maestro inicia la clase de Música, da las indicaciones sin dirigirse de manera específica a Abril. Durante la actividad, el maestro no se coloca frontalmente a ella para facilitarle la lectura de los labios; se encuentra lejos, por lo que no puede seguirlo y entender lo que expresa, se distrae. El maestro se sienta en una silla con su guitarra, frente a los niños, los cuales están situados en el piso. Les dice que tocará la canción "Bartolito el gallo" y que, mientras canta, ellos escucharán el nombre de un animal, del cual emularán el sonido que emite, por lo que deben de prestar mucha atención. Abril no deja de ver la boca del maestro para leerle los labios y seguir la indicación, también con gestos le pregunta a su prima lo que van a hacer y su prima le dice: "Cantaremos". Empieza a cantar: 


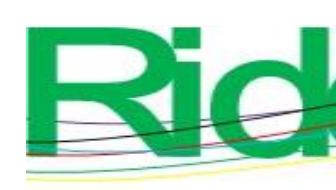

Revista Iberoamericana para la Investigación y el Desarrollo Educativo ISSN $2007-7467$

— Bartolito era un gallo que vivía muy feliz. Cuando el sol aparecía Bartolito cantaba así.

El maestro grita “ipato!” y los niños gritan “cuac, cuac, cuac”. Abril voltea a ver a sus compañeros, cuando gritan el sonido del pato, ella abre la boca imitando lo que hace su prima, después voltea a ver al maestro, quien continúa cantando, mueve la cabeza siguiendo el ritmo y sonríe (observación número cinco).

Nuevamente, las instrucciones y la actividad misma no se adecúan a las condiciones de Abril, por lo que ella no puede comprender las indicaciones ni los contenidos de esta, aunque muestre cierta complacencia con su accionar.

En actividades de juego también disfruta, ríe y comparte con sus compañeros a plenitud. Siempre que no haya una ejecución que no pueda realizar, se muestra alegre y goza su estancia en el preescolar. Sin embargo, se debe considerar que en cualquier situación encuentra dificultades para seguir la actividad, pues el maestro no brinda el apoyo adecuado; en consecuencia, no comprende y, por extensión, sus aprendizajes son limitados. Ella imita a sus compañeros oyentes, tratando de dar sentido a una actividad que, a todas luces, no está diseñada para ella. Posee adecuada capacidad de imitación y aparente adaptación, lo cual hace pensar que logra los aprendizajes esperados, pero realmente no ha sido así.

Todos los maestros conocen de las dificultades de Abril y advierten que el colocarse visualmente cercanos a ella es importante para que atienda y comprenda las indicaciones y evite que se distraiga; no obstante, en la práctica, no siempre ocurre así. De haber realizado algún señalamiento acerca de su condición de discapacidad, probablemente hubiese tenido un efecto contrario; y, al menos en términos de su participación, ello ha sido sumamente meritorio:

Tratar a estos niños de manera especial como en una esfera de cristal, eso no está bien, al contrario (entrevista número nueve al maestro de música).

Y en esa misma tónica:

Nunca se le ha hecho alguna diferencia, pues ella participa de manera voluntaria, jamás nos dijo “¡no!”, o se negó. Inclusive, en algunos eventos, ella llevaba el papel principal, y lo único que hacíamos era hablarle más fuerte (entrevista número cinco a la maestra de educación física).

Los mitos que han existido a través del tiempo sobre las personas sordas solo generan prejuicios sociales y limitan la relación entre personas sordas y oyentes. La maestra de 


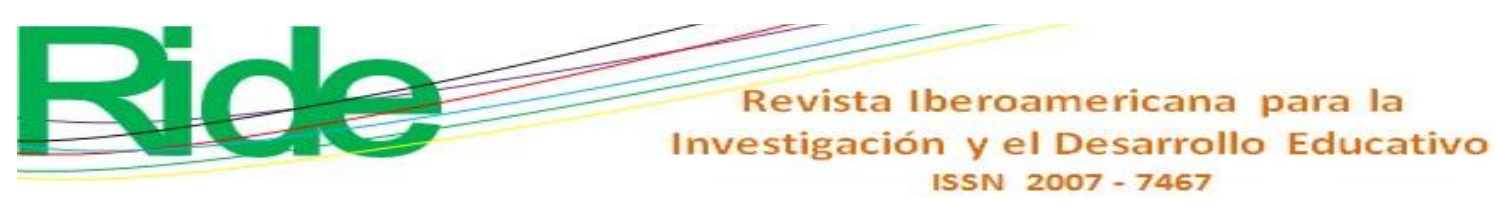

Educación Física asume que, debido a que la niña no presenta un problema motor, no hay necesidad de algún tipo de adecuación curricular; no considera otros procesos como la comprensión de las instrucciones, su socialización o los vínculos que establezca:

Abril no presenta ninguna dificultad para realizar las actividades y solo requiere de cierta ayuda, por lo que no tenemos que hacer ninguna adecuación con ella, porque ella no tiene ningún problema de tipo motor (entrevista número siete).

El apoyo se centra en la reiteración de las instrucciones, no tanto en su comprensión: A Abril entre todos los compañeritos le ayudábamos (...). Cuando trabajamos con manipulación de objetos, y decimos lo vamos a hacer con la mano derecha, mano izquierda, ella lo hace con las dos manos, pero ahí es donde la apoyamos. Se le cayó, que no se caiga; [le dice]: "No le hace, mamita, levántalo y vuélvelo a hacer", o sea, ya tenemos que poner un poquito de apoyo con ellos (entrevista número siete a la maestra de educación física).

Este es un aspecto conocido por las maestras del Centro de Atención Múltiple. Una de ellas señala:

En las escuelas regulares no se elaboran programas con adecuaciones curriculares, aun cuando tengan alumnos con dificultades. El no elaborarlo les crea ciertas dificultades para trabajar con el niño (...), para atender adecuadamente su necesidad. La planeación que el maestro elabora es de manera general, sin tomar en cuenta (...) las necesidades de cada alumno a su cargo (entrevista número uno).

Esta situación no es compartida por la maestra de aula regular, quien señala que no reciben formación u otros apoyos para la atención de estos alumnos. Las maestras desconocen las políticas públicas orientadas al manejo de alumnos con discapacidad, en general o con sordera. Esto las lleva a actuar y a tomar decisiones sobre la enseñanza de Abril, incluso, en ocasiones, vulnerando sus derechos. Ejemplo de ello es el no enseñarle la lengua de señas mexicana (LSM).

Cuando entramos a lo de la integración educativa, nos dieron un curso y nos dijeron que tenemos que tratar a todos los niños y niñas por igual, o sea, no hubo ningún curso especial para tratar a niños sordos o niños Down, para tratar otro tipo de capacidades diferentes, o sea, nosotros trabajamos igual para todos, no hay que si voy a hacer un material especial para ella. 


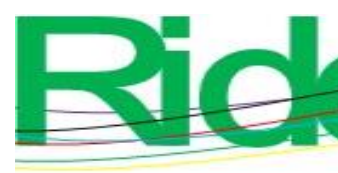

Revista Iberoamericana para la
Investigación y el Desarrollo Educativo
ISSN $2007-7467$

El desarrollo de una enseñanza y actividades escolares uniforme a todos los alumnos, así como el uso exclusivo de la lengua oral en la comunicación, resulta especialmente incompatible con una atención educativa que atienda a las diferencias y diversidad del alumnado, como en el caso de Abril.

Ambos profesionales privilegian el aprendizaje de contenidos y si ello se logra, entonces el trabajo se considera exitoso, sobre todo si en su aprendizaje "no existe mucha diferencia entre ella y sus compañeros" (entrevista número cuatro a la maestra de grupo). Se relegan dimensiones como la lengua de signos como medio primario de comunicación, las de socialización y desarrollo del lenguaje oral.

Otro de los aspectos que median las posibilidades de atención a este alumnado es el número de estudiantes por grupo, que regularmente son de 40 o más, por lo que resulta sumamente difícil su atención a la par del resto.

\section{Pertrechos y faltas en la estructuración sociocognitiva y la convivencia social}

Abril realiza la lectura de labios, lo que le permite llevar a cabo algunas de las actividades escolares, aparentemente sin dificultad, por lo que sus compañeros no perciben su condición y los problemas de comprensión de la tarea. La maestra de aula regular lo expresa así:

Ella fija mucho la vista, atiende mucho con la vista, tiene muy desarrollado este sentido y ella ve y hace lo que sus compañeros (...). Ella, de manera general, pone atención, o sea, ella me ve, ella lee los labios (...), pregunta, ella pregunta, puede ser a mí o puede a sus compañeros (entrevista número tres).

La alumna muestra competencias en distintas actividades, como en las de Educación Física, espacio en el que, además, despliega amplia participación:

Todas las actividades de Educación Física ella las realiza como todos en la clase, tiene ritmo, equilibrio (...), pide a su maestra participar en todos los eventos que están programados en el ciclo escolar (entrevista número cinco a la maestra de Educación Física).

Cuando existe una pérdida auditiva importante desde el nacimiento, o antes de desarrollar el lenguaje, se presentan alteraciones en el desarrollo lingüístico, cognitivo, 


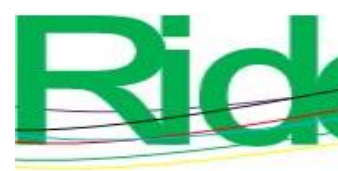

Revista Iberoamericana para la Investigación y el Desarrollo Educativo ISSN $2007-7467$

emocional, afectivo y social. Ser sordo no supone incapacidad para el desarrollo personal o la adaptación social. Un niño que presenta una discapacidad auditiva tiene las mismas posibilidades intelectuales y de crecimiento que el niño oyente, pero necesita de intervenciones específicas para dar respuesta a su particular ritmo y forma de aprendizaje.

Además, el copiado de grafías o numerales, lo mismo que las actividades de recorte, son tareas que lleva a cabo, lo que demuestra la capacidad de aprender.

La maestra de aula regular percibe a la niña como proactiva, participativa, respetuosa, no conflictiva y con cierta pasividad. Su lenguaje es reducido, aunque complementa estas carencias con la observación, la lectura de labios y señas. En su enseñanza, es importante reconocer el derecho a una educación bilingüe. La lengua de señas debe emplearse como primera lengua de los niños sordos, mientras que la lengua oral debe ocupar un segundo lugar. "No es conflictiva. Aunque en ocasiones la agreden, ella no responde con agresión, a veces responde con llanto, pero de manera general es pasiva, no falta a la escuela" (entrevista número tres).

Las relaciones entre Abril y sus compañeros son armónicas. Para la maestra, que ellos la acepten y le muestren afecto constituye una muestra del trabajo educativo.

En cuanto al grupo, la aceptan ante su necesidad auditiva, ellos ¡la aceptan! Ayer todavía la estaba yo viendo que la estaba abrazando Naomí, la tenía abrazada y la estaba besando, o sea, ¡la quieren, la aceptan como es!, pero ese trabajo ya viene de atrás porque (...) se niegan tajantemente agresiones hacia ella; no obstante la malformación en su rostro, de que le digan que está fea, o por qué estás así, no, no, ¡nadie ha dicho nada! ¡Nadie la ha molestado!, ¡nadie le ha dicho nada! (entrevista número tres).

Los maestros asumen una relación de afecto entre ellos y la alumna:

Ella me quiere mucho, por decir, por lo regular los niños quieren mucho a sus maestros de Música y a su maestro de Educación Física, porque son materias, digamos, de diversión, de desfogue, de descarga (entrevista número ocho al maestro de música).

La relación hacia Abril presenta tintes de rechazo o agresión, aunque haya un esfuerzo por los educadores de socavar estas acciones.

Desde el punto de vista del desarrollo socioafectivo, la falta de audición interfiere las condiciones de proximidad, y la capacidad de identificar los sentimientos, lo mismo que el disfrute de diferentes percepciones a partir de la audición como la música (Pabón, 2009). En 


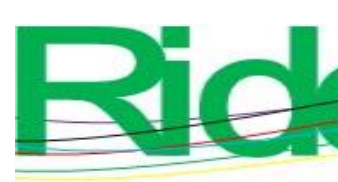

Revista Iberoamericana para la Investigación y el Desarrollo Educativo ISSN $2007-7467$

su interacción con los demás, la expresión de afecto por parte de Abril es nula o muy limitada, como ocurre ante la llegada del propio maestro de Música al salón de clases:

Los niños corren a abrazarlo, lo rodean saltando, contentos y sonrientes de salir, el maestro les pide que se calmen y se ordenen para ir al corredor, que es donde será la clase. Abril sonríe, pero no se acerca a abrazar al maestro como los demás niños (observación número cinco).

También muestra interés por otros niños, escarceos a lo que los adultos denominan atracción por los otros, aunque esto implique tal vez el jugar con ellos o mantener una charla. Ahí resulta evidente su retraimiento social.

En su relación con los demás niños, ella mantiene vínculos de gustarle un niño, aunque ningún niño ha manifestado una preferencia por ella, a ella ¡nunca nadie le ha dicho que es su novia!, ¡nunca nadie!, ¡ella sí dice que le gusta Emerson o que le gusta Joaquín!, todo esto lo sé porque su prima lo dice, ya que Abril sí habla, lo hace muy despacito y casi no se logra entender y escuchar (entrevista número tres a la maestra de grupo).

Se le percibe como integrada a las actividades y el juego, lo que los maestros intentan y logran la mayor parte de las veces en el trabajo que realizan.

Ella participa de manera selectiva en los juegos con cierto número de niñas, pero de manera general no presenta dificultad para relacionarse, juega con sus compañeros de mesa, pero como todos los demás niños, también presenta peleas y agresiones. Abril realiza todas las actividades sin excluirse, cuando se le dificulta algo, ella observa y vence el obstáculo (entrevista número tres a la maestra de grupo).

Empero, en entornos no dirigidos por ellos, como el recreo o la salida de la escuela, se aprecian limitaciones en la interacción social, o esta se establece casi exclusivamente con su prima, lo que deviene en aislamiento o rechazo de algunos compañeros.

Existe cierto aislamiento de su parte e incluso rechazo por otros niños, aunque ella no presenta conductas agresivas. A pesar de su dificultad para escuchar, es aceptada por sus compañeras, aunque siempre se le ve con su prima y Alexia, quienes siempre la aceptan para integrarla a sus juegos y mientras juega, Abril no se separa de su prima (entrevista número ocho al maestro de música). 


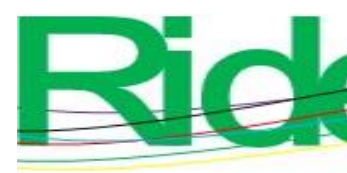

Revista Iberoamericana para la
Investigación y el Desarrollo Educativo
ISSN $2007-7467$

En esa misma línea: “Abril fue a jugar con su prima. Durante el recreo, solo juega con ella, a veces se acerca Alexia, que es otra amiga, corren de un lado a otro, sin usar palabras, solo sigue a su prima o amiga" (observación número seis).

La relación con sus compañeros orbita entre el apoyo y ciertos desencuentros, los que le llevan a exacerbar su aislamiento y dependencia de su prima, compañera de grupo.

El grupo camina en una fila desde el salón de clases, llegan al patio y se acercan a la maestra. Al formarse, una de las niñas quería quedar delante de ella, por lo que empezó a empujarla. Abril optó por irse más atrás de la fila junto con Ivonne (prima de Abril). La maestra no dijo nada ante ello (observación número cuatro).

Por otra parte, la falta de apoyos auxiliares adecuados, lo mismo que su mantenimiento, son impedimentos para un mejor desarrollo y desempeño escolar.

Abril tiene discapacidad auditiva de $50 \%$ o un poco más, ¡sí escucha, pero no $100 \%$ ! Diría que solo escucha como $40 \%$, aunque ella tiene auxiliares, no siempre los utiliza, no los usa porque este aparato requiere de cierto mantenimiento específico, además es caro y debe hacerse periódicamente (entrevista número tres a la maestra de grupo).

La madre de la niña también es sorda, por lo que dicha vivencia no es nueva ni tampoco le es desconocida; sin embargo, la comunicación que mantiene con la hija es a través de señas caseras, ya que no se observó que manejara la LSM y el desconocimiento del lenguaje de señas limita aún más su situación. La precaria situación económica y ausencia familiar por el trabajo realizado las colocó en una situación por la cual ambas no accedieron a esta lengua o a una comunidad sorda. El uso de los audífonos fue temporal, cuando le fueron proporcionados por personal de una dependencia gubernamental, pero por los costos y mantenimiento no le fue posible continuar con este.

Es la abuela materna quien se ocupa de atenderla, prodigarle afecto y acudir por ella a la escuela.

Abril vive sola con su madre y sus abuelos (...). La mamá de Abril también es sorda, pero el de ella es más severa la pérdida auditiva. Lo que sí he observado es que, entre ellas, cuando hablan, no usan la LSM; se comunican con las señas comunes y corrientes, no hay un lenguaje signado (señas que utilizan la comunidad sorda, LSM) o lengua a señas. De vez en cuando, la 


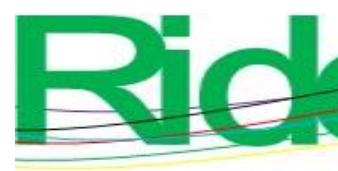
Revista Iberoamericana para la
Investigación y el Desarrollo Educativo
ISSN $2007-7467$

mamá apoya en algunas actividades escolares, pero es evidente que el apoyo mayor es con la abuela.

A la hora de la salida, quien llega a recoger a Abril es su abuelita. Mientras está en compañía de ella, no se le separa, solo en ciertas ocasiones, como cuando recibe indicaciones de la maestra. La abuela presta atención a todos sus movimientos y le responde de igual forma, marcando la gesticulación de la boca para que ella pueda leer sus labios y entienda lo que le dice (observación número tres).

\section{Discusión}

Los docentes no establecen diferencias en el trabajo áulico con Abril. Esta situación se presenta cuando se implementan estrategias pedagógicas de repetición y copia de acciones carentes de sentido para la alumna, el currículo que se implementa no la contempla y es desarrollado solo para una comunidad oyente, aunque esto la lleve a la búsqueda de acciones alternas para compensar las dificultades que la tarea le presenta. Ello ha contribuido también a que sus compañeros no tomen en cuenta u olviden la condición de sordera de la niña, a la vez que la coloca en una situación de seudoigualdad. En suma, sus compañeros no entienden qué le pasa, pues todos saben que tiene algo porque no actúa como ellos y, cuando surgen preguntas al respecto, la maestra expresa que hay que tener paciencia y tolerancia porque ella es distinta a los demás, pero que a la vez es como todos. Tal condición relacional crea una narrativa de socialización en que la diferencia se asume como un principio de la práctica docente que se nutre de saberes morales y sociales (Brogna, 2006).

En contraparte, las secuencias didácticas en las que participa la alumna probablemente no atienden del todo a su interés y necesidades, tal práctica requiere "descolonizar las construcciones que hay frente al sujeto y a sus procesos de aprendizaje" (Caballero, Ocampo y Restrepo, 2018, p. 169). En tal sentido, la atribución hacia la niña de dificultades atencionales olvida la importancia que tiene el apoyo diferenciado hacia ella en las consignas de clases, a lo que se aúna la falta de acciones que minimicen sus limitaciones sensoriales en el ámbito comunicativo, con lo que el aula escolar y la escuela aparecen en ciertos momentos como un espacio construido para otros en el que se siente extraña y ajena (Vesga y Vesga, 2015). 


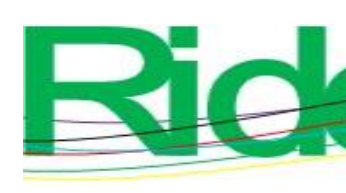

Revista Iberoamericana para la Investigación y el Desarrollo Educativo ISSN $2007-7467$

La elaboración y aplicación de las adecuaciones curriculares es un motivo que tensa las relaciones entre los docentes de escuela regular y especial. Estos últimos plantean que sin estos recursos se tienen dificultades en el trabajo con los alumnos; sin embargo, tampoco se precisa el ámbito o dimensiones de desarrollo que ello debe considerar: se privilegia el aprendizaje de contenidos y el desarrollo socioafectivo y sobre todo la enseñanza de la lengua de señas son eludidos. La aplicación de saberes profesionales es todavía un pendiente en la actividad práctica de los docentes (Carr y Kemmis, 1988).

La maestra aprecia que Abril mantenga una adecuada relación con sus compañeros, ya que le aceptan. Parece que ello tendría que ser un aspecto que debiese formar parte de la relación, aceptar al otro como preludio del encuentro; el otro diferente sensorialmente es aceptado en una acción que tiene el otro social ante el otro diverso. Hay un imaginario subyacente en el cual un principio social debe ser la aceptación del otro social hacia el otro diferente, pero difícilmente se expone lo contrario.

La expresión afectiva es una acción que da cuenta de ello, pero ¿es una situación que los niños deben reconocer?, o ¿es el adulto quien debe asumir un posicionamiento en que el afecto no sea dádiva? Las agresiones se sancionan, pero en algunos momentos ello no ocurre así; además, la malformación física y la ingenua, pero lacerante pregunta sobre ello por los demás tiende a socavar su entusiasmo e inhibirla en el contacto social.

El atender de manera enfática una situación como esta, por parte de los docentes, pudiera devenir en su sobreprotección, o al menos una consideración de ese tipo por parte de los compañeros. Dejar que resuelva por sí misma dichas situaciones resulta también una apuesta en la que se aprecian pocos recursos y apoyos por parte de sus pares hacia ella.

\section{Conclusiones}

Las políticas de educación inclusiva consideran las diferencias individuales en la atención de las necesidades de los alumnos y alumnas. En el caso de los escolares con sordera, la atención a sus necesidades educativas de comunicación deberá basarse en la LSM y secundariamente en la lengua española, además de que en el entorno de escuelas regulares es conveniente contar con unidades especiales.

Aunque las políticas gubernamentales expresan la necesidad de crear ambientes inclusivos para los niños sordos en las aulas regulares, lo que se devela es que es apartado 


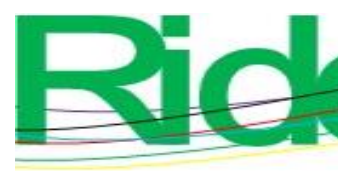

Revista Iberoamericana para la Investigación y el Desarrollo Educativo ISSN $2007-7467$

acompañamiento más allá de la escuela a estos niños y a sus familias, capaz de proveerles desde temprana edad de atención especializada a raíz de la alteración auditiva que presentan, de forma gratuita, de auxiliares con tecnología de punta y su mantenimiento, así como el apoyo de bienes materiales y simbólicos.

La práctica docente es el hiato que expande el análisis de la dinámica escolar a los bordes de la vida familiar y social, sin circunscribir la problemática a los aspectos estrictamente curriculares, pedagógicos, didácticos y de sus actores, ya que hala de las significaciones e implicaciones de los modelos con lo que se concibe a escolares con discapacidad auditiva, de la consideración a sus derechos y luchas. Si dicha práctica no se acompaña, en el caso de alumnos con sordera, de una enseñanza que privilegie la lengua de señas las expectativas de éxito son nulas. La experiencia del estudio registra tales dificultades cuando se atiende a una alumna con esta condición en aulas de escuelas regulares con clases en español. En contraparte, una enseñanza que se realice con lengua de señas supone una atención pedagógica específica, adaptada, personalizada, de plena inclusión.

\section{Futuras Líneas de Investigación}

En futuros trabajos de investigación es necesario profundizar en la situación de personas con condición de sordera en que la enseñanza se realice con la lengua de señas; visibilizar la presencia y la participación de la comunidad sorda en las aulas regulares, de tal manera que, a partir de sus experiencias de vida, de las formas de construir su realidad, sus expectativas y sus necesidades, se brinde una educación en la que sus diferencias sean atendidas y reconocidas para brindar una educación con equidad en las que se protejan al niño sordo, su lengua y su cultura; así como el papel que juega la familia en la enseñanza y acompañamiento escolar de estos alumnos. 


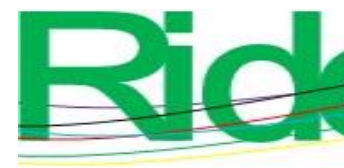

Recuperado

https://www.unicef.org/spanish/publications/files/Un_enfoque_de_la_EDUCACIO N_PARA_TODOS_basado_en_los_derechos_humanos.pdf.

García, F. J. y Herrero, J. (2008). Manual de atención al alumno con necesidades específicas de apoyo educativo derivadas de discapacidad auditiva. España: Consejería de Educación. Recuperado de https://sid.usal.es/idocs/F8/FDO23840/apoyo_educativo_discapacidad_auditiva.pdf.

Herrera, V. (2009). Intervención temprana en niños sordos y sus familias. Un programa de atención integral. Revista Electrónica Diálogos Educativos, 9(17), 74-88 Recuperado de https://dialnet.unirioja.es/servlet/articulo?codigo=3039072.

Litwin, E. (2008). El oficio de enseñar. Condiciones y contextos. Buenos Aires, Argentina: Paidós.

Marchesi, A., Coll, C. y Palacios, J. (2014). Desarrollo psicológico y educación. Tomo 3. Trastornos del desarrollo y necesidades educativas especiales. Psicología y educación (2. ${ }^{\mathrm{a}}$ ed.). España: Alianza Editorial.

Organización de las Naciones Unidas para la Educación, la Ciencia y la Cultura [Unesco]. (1994). Declaración de Salamanca y Marco de Acción para las Necesidades Educativas Especiales. Salamanca, España: Organización de las Naciones Unidas para la Educación, la Ciencia y la Cultura. Recuperado de https://www.unioviedo.es/ONEO/wpcontent/uploads/2017/09/Declaraci\%C3\%B3n-Salamanca.pdf.

Pabón, S. (2009). La discapacidad auditiva. ¿Cómo es el niño sordo? Revista Digital Innovación y Experiencias Educativas, 16, 1-10. Recuperado de https://archivos.csif.es/archivos/andalucia/ensenanza/revistas/csicsif/revista/pdf/Nu mero_16/SABINA_PABON_2.pdf.

Peterson, C. C. (2004). Theory-of-Mind Development in Oral Deaf Children with Cochlear Implants or Conventional Hearing Aids. Journal of Child Psychology and Psychiatry, 45(6), 1096-1106. Retrieved from https://eric.ed.gov/?id=EJ951596.

Peterson, C. C. and Siegal, M. (1999). Representing Inner Worlds: Theory of Mind in Autistic, Deaf and Normal Hearing Children. Psychological Science, 10(2), 126-129. Retrieved from https://journals.sagepub.com/doi/10.1111/1467-9280.00119.

Petitto, L. A., Katerelos, M., Levy, B. G., Gauna, K., Tétreault, K. and Ferraro, V. (2001). Bilingual signed and spoken language acquisition from birth: implications for the 


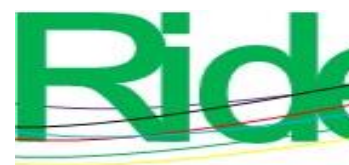

Revista Iberoamericana para la
Investigación y el Desarrollo Educativo
ISSN $2007-7467$

mechanisms underlying early bilingual language acquisition. Journal of Child Language, 28(2), 453-496. Retrieved from https://www.pnas.org/content/pnas/97/25/13961.full.pdf.

Puigdellívol, I. (2000). La educación especial en la escuela integrada. Barcelona, España: Editorial Graó.

Puigdellívol, I. (2003). La educación especial en la escuela integrada. Barcelona, España: Editorial Graó.

Ricoy, M. C. (2005). La prensa como recurso educativo. Revista Mexicana de Investigación Educativa, $\quad$ 10(24), $\quad$ 125-163. Recuperado de https://www.redalyc.org/pdf/140/14002407.pdf.

Schorn, M. E. (2009). La capacidad en la discapacidad: sordera, discapacidad intelectual, sexualidad y autismo (3. a ed.). Buenos Aires, Argentina: Lugar Editorial.

United Nations Educational Scientific and Cultural Organization [Unesco]. (2005). Guidelines for Inclusion. Ensuring Access to Education for All. Paris, France: United Nations Educational Scientific and Cultural Organization. Retrieved from http://www.ibe.unesco.org/sites/default/files/Guidelines_for_Inclusion_UNESCO_2 006.pdf.

Vázquez, C. M. y Martínez, R. (2003). Guía para la atención educativa a los alumnos y alumnas con discapacidad auditiva. Sevilla, España: Consejería de Educación y Ciencia de la Junta de Andalucía. Recuperado de http://ardilladigital.com/DOCUMENTOS/DISCAPACIDADES/SENSORIAL/AUD ITIVA/Guia\%20atencion\%20educativa\%20discapacidad\%20auditiva\%20\%20Junta\%20Andalucia\%20-\%20libro.pdf.

Vesga, L. y Vesga, J. (2015). Una exclusión que se perpetúa: tensiones entre docentes, niños sordos y niños oyentes en escenarios escolares de Popayán. Revista Virtual Universidad Católica del Norte, 3(46), 115-128. Recuperado de http://revistavirtual.ucn.edu.co/index.php/RevistaUCN/article/view/703/123.

World Federation of the Deaf [WFD]. (2018). WFD Position Paper on Inclusive Education. Retrieved from https://wfdeaf.org/wp-content/uploads/2018/07/WFD-PositionPaper-on-Inclusive-Education-5-June-2018-FINAL-without-IS.pdf 


\begin{tabular}{|c|c|}
\hline Rol de Contribución & Autor (es) \\
\hline Conceptualización & Soledad Hernández Solís (principal) \\
\hline Metodología & $\begin{array}{l}\text { Soledad Hernández Solís (principal) Germán Alejandro García } \\
\text { Lara (igual) Óscar Cruz Pérez (apoyo) }\end{array}$ \\
\hline Software & NO APLICA \\
\hline Validación & $\begin{array}{l}\text { Soledad Hernández Solís (principal) Germán Alejandro García } \\
\text { Lara (igual) }\end{array}$ \\
\hline Análisis Formal & $\begin{array}{l}\text { Soledad Hernández Solís (principal) Germán Alejandro García } \\
\text { Lara (igual) Irma Hernández Solís (apoyo) Óscar Cruz Pérez } \\
\text { (apoyo) Carlos Eduardo Pérez Jiménez (apoyo) }\end{array}$ \\
\hline Investigación & $\begin{array}{l}\text { Soledad Hernández Solís (principal) Germán Alejandro García } \\
\text { Lara (igual) Irma Hernández Solís (apoyo) Óscar Cruz Pérez } \\
\text { (apoyo) Carlos Eduardo Pérez Jiménez (apoyo) }\end{array}$ \\
\hline Recursos & $\begin{array}{l}\text { Soledad Hernández Solís (principal) Germán Alejandro García } \\
\text { Lara (igual) Irma Hernández Solís (apoyo) Óscar Cruz Pérez } \\
\text { (apoyo) Carlos Eduardo Pérez Jiménez (apoyo) }\end{array}$ \\
\hline Curación de datos & $\begin{array}{l}\text { Soledad Hernández Solís (principal) Germán Alejandro García } \\
\text { Lara (igual) Irma Hernández Solís (apoyo) Óscar Cruz Pérez } \\
\text { (apoyo) Carlos Eduardo Pérez Jiménez (apoyo) }\end{array}$ \\
\hline $\begin{array}{l}\text { Escritura - Preparación del } \\
\text { borrador original }\end{array}$ & $\begin{array}{l}\text { Soledad Hernández Solís (principal) Germán Alejandro García } \\
\text { Lara (igual) }\end{array}$ \\
\hline $\begin{array}{l}\text { Escritura - Revisión y } \\
\text { edición }\end{array}$ & $\begin{array}{l}\text { Soledad Hernández Solís (principal) Germán Alejandro García } \\
\text { Lara (igual) Irma Hernández Solís (apoyo) Óscar Cruz Pérez } \\
\text { (apoyo) Carlos Eduardo Pérez Jiménez (apoyo) }\end{array}$ \\
\hline Visualización & $\begin{array}{l}\text { Soledad Hernández Solís (principal) Germán Alejandro García } \\
\text { Lara (igual) Irma Hernández Solís (apoyo) Carlos Eduardo } \\
\text { Pérez Jiménez (apoyo) Óscar Cruz Pérez (apoyo) }\end{array}$ \\
\hline Supervisión & $\begin{array}{l}\text { Soledad Hernández Solís (principal) Germán Alejandro García } \\
\text { Lara (igual) Irma Hernández Solís (apoyo) Carlos Eduardo } \\
\text { Pérez Jiménez (apoyo) Óscar Cruz Pérez (apoyo) }\end{array}$ \\
\hline $\begin{array}{l}\text { Administración } \\
\text { Proyectos }\end{array}$ & Soledad Hernández Solís (principal) \\
\hline Adquisición de fondos & Soledad Hernández Solís (principal) \\
\hline
\end{tabular}

